\title{
КОМПЛЕКСНАЯ ЭКОЛОГИЧЕСКАЯ ОЦЕНКА СОСТОЯНИЯ ЗЕЛЕНЫХ НАСАЖДЕНИЙ В ПАРКЕ ИМ. И.П. КУЛИБИНА ГОРОДА НИЖНЕГО НОВГОРОДА
}

\section{INTEGRATED ENVIRONMENTAL ASSESSMENT OF THE CONDITION OF GREEN PLANTS IN THE PARK IM. I.P. KULIBINA CITY NIZHNY NOVGOROD}

I. Vershinina

E. Ryabova

Summary. The article presents an assessment of the vital state, aesthetic properties and phytopathological characteristics of tree and shrub plantations in the park named after V.I. P.I. Kulibin, located in the central part of Nizhny Novgorod. Green spaces occupy more than 79\% of the total area of the park. It was found that the forest stand of the park is dominated by small-leaved linden, plantavid maple shoots and common hawthorn. More than $30 \%$ of all deciduous species are in a strongly weakened state and are in dire need of crowning, treatment of trunks, pruning of dry branches. The unsatisfactory sanitary condition of trees is associated with drying out and the development of pathological processes, the presence of necrotic cancerous and rotten diseases of various etiologies.

Keywords: green spaces, park, ecological frame, dominants, ecological assessment, life state, pathology.

\author{
Вершинина Ирина Валерьевна \\ К.б.н., дочент, ФГБОУ ВО «Нижегородский \\ государственный педагогический университет \\ им. К. Минина» \\ vershinina.iv@gmail.com \\ Рябова Евгения Павловна \\ ФГБОУ ВО «Нижегородский государственный \\ педагогический университет им. К. Минина» \\ riabova_97@mail.ru
}

Аннотация. В статье представлена оценка жизненного состояния, эстетических свойств и фитопатологическая характеристика древесно-кустарниковых насаждений парка им. П.И. Кулибина, расположенного в центральной части г. Нижего Новгорода. Зеленые насаждения занимают более $79 \%$ от общей площади территории парка. Установлено, что в составе древостоя парка доминируют липа мелколистная, поросль клена плантавидного и боярышник обыкновенный. Более $30 \%$ всех лиственных пород находятся в сильно-ослабленном состоянии и остро нуждаются в кронировании, лечении стволов, обрезке сухих веток. Неудовлетворительное санитарное состояние деревьев выражено усыханием и развитием патологических процессов, наличием некрозно-раковых и гнилевых заболеваний различой этиологии, и обусловлено возрастом зеленых насаждений и воздействием ряда стрессовых факторов.

Ключевые слова: зеленые насаждения, парк, экологический каркас, доминанты, экологическая оценка, жизненное состояние, патология.

ном снижении качества компонентов природной среды, уменьшении биологического разнообразия, снижении средообразующих, эстетических и рекреационных функций городского ландшафта, прямым следствием чего становится ухудшение состояния здоровья населения» [6]. Сохранение качественных показателей состояния зеленых насаждений в условиях городской среды позволяет создать благоприятные условия для нормальной жизнедеятельности человека на урбанизированных территориях. Важным аспектом поддержания оптимального состояния растительности парков и скверов являются системные мониторинговые исследования экологического состояния зеленого фонда урбоэкосистемы.

\section{Материалы и метолы}

Парк имени И.П.Кулибина расположен в Нижегородском районе г.Н. Новгорода. Парк ограничен 


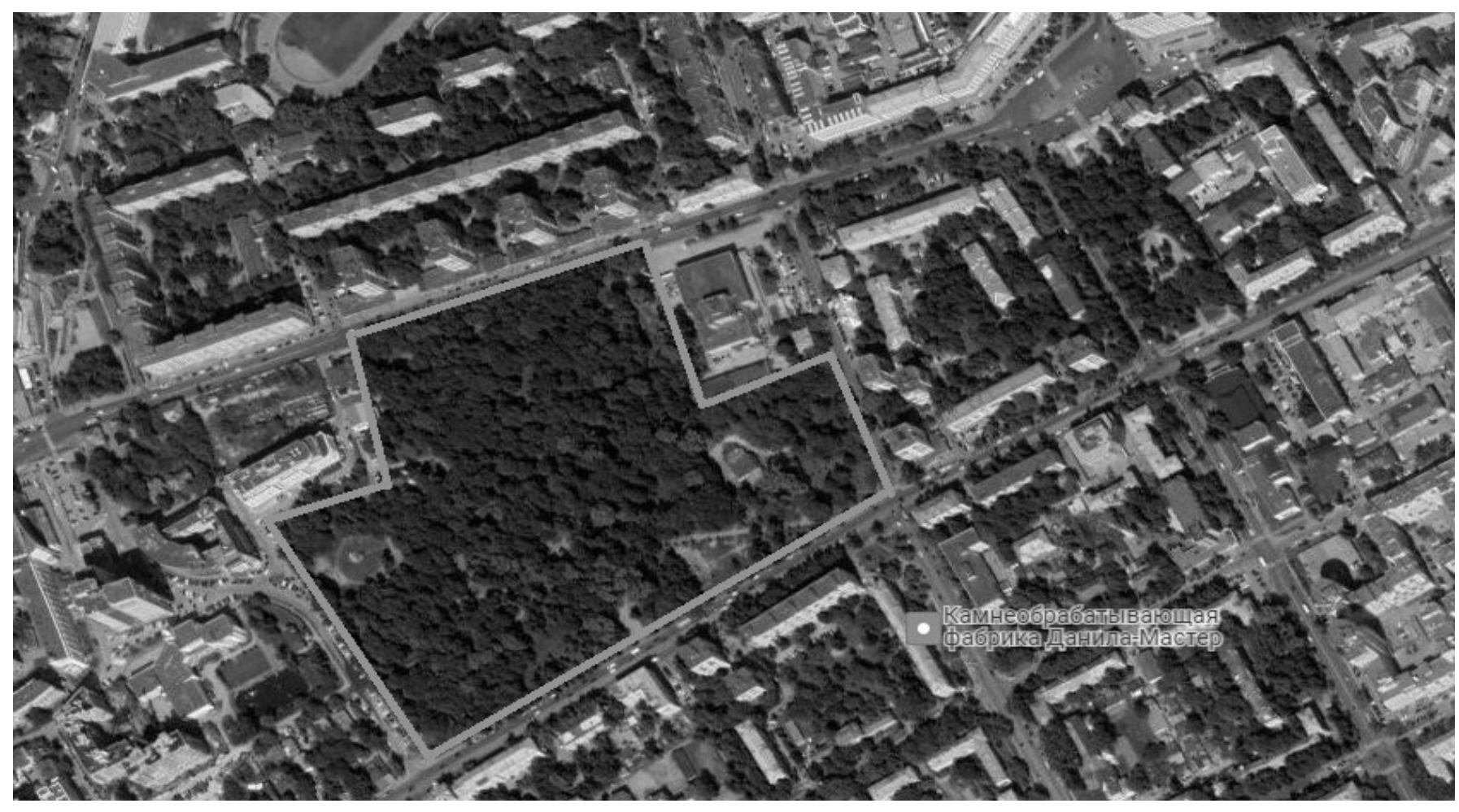

Рис 1. Парк им. И.П. Кулибина (Google-Карты: вид со спутника)

с северной стороны улицей М. Горького, а с южной улицей Белинского, с запада на восток его территория заключена между Ашхабадской и Ошарской улицами. Таким образом, парк расположен между улицами с плотным транспортным движением и граничит с жилой и общественной застройкой.

Общая площадь парка составляет 98998 кв.м, при этом площадь территории, занятой зелеными насаждениями составляет более 79\%. Парк имени Кулибина включен в реестр озелененных территорий общего пользования (ОТОП) г. Н. Новгорода. Городской парк им. Кулибина отличается среди всех иных парков и скверов центральной части Н. Новгорода, в первую очередь, своим мемориально-историческим значением. Он основан в 1937 г. на месте Всесвятского Петропавловского кладбища, где был похоронен выдающийся нижегородец - механик-самоучка И.П. Кулибин.

Планировка и структура парка им. И.П. Кулибина сложились исторически и обусловлена целевым назначением функциональных зон, месторасположением и характером существующих насаждений. План реконструкции парка разработан и осуществлен в 1987 г. институтом «Горьковгражданпроект», и отражает современную планировочную ситуацию [7]. Для парка им. И.П. Кулибина характерно наличие открытых, полуоткрытых и закрытых пространств, которые, наряду с исторически сложившимися объектами, диктуют расположение функциональных зон и парковых элементов на его территории.

Рельеф парка имеет небольшой уклон на юго-восток. Почвы представлены антропогенно преобразованными техногенными грунтами, преимущественно насыпными с каменистыми включениями и прослойками. Для них характерно уплотнение верхних горизонтов и наличие строительного и прочего мусора. Территория парка им. И.П. Кулибина имеет оптимальный водный режим. Зеленые насаждения парка представлены древесно-кустарниковой растительностью с преобладанием лиственных пород. Нижний ярус сформирован кустарниками: порослью клёна плантавидного (Acer platanoides L.), боярышником обыкновенным (Crataegus laevigata (Poir.) DC.), спиреей Вангутта (Spiraea vanhouttei (Briot) Zabel). Рекреационная нагрузка на территории парка им И.П. Кулибина распределена равномерно.

Категории жизненного состояния зеленых насаждений осуществляли по методике Б.Г. Нестерова. Ослабление состояния древесно-кустарниковых культур характеризовали методом расчета средневзвешенной величины на основании оценок категорий состояния зеленых насаждений: 1 - здоровое, 2 - ослабленное, 3 - сильно ослабленное, 4 - усыхающее, 5 - свежий сухостой. 
Таблица 1. Видовой состав, категории жизненного состояния и уровень эстетической оценки древесной растительности, произрастающей на территории парка им. И.П. Кулибина г. Н. Новгорода

\begin{tabular}{|c|c|c|c|c|c|c|c|}
\hline \multirow[t]{2}{*}{ Наименование древесной культуры } & \multirow{2}{*}{$\begin{array}{l}\text { Кол-во, } \\
\text { (экз) }\end{array}$} & \multirow[t]{2}{*}{ Доля,\% } & \multicolumn{4}{|c|}{$\begin{array}{l}\text { Категория } \\
\text { Эстетическая оценка }\end{array}$} & \multirow{2}{*}{$\begin{array}{l}\text { Kср. } \\
\text { Кэ }\end{array}$} \\
\hline & & & 1 & 2 & 3 & 4 & \\
\hline \multicolumn{8}{|l|}{ Деревья лиственных пород } \\
\hline \multirow{2}{*}{ Липа сердцевидная (Tilia cordata Mill.) } & \multirow{2}{*}{504} & \multirow{2}{*}{30,1} & 88 & 268 & 11 & 34 & \multirow{2}{*}{$\begin{array}{l}1,6 \\
1,6\end{array}$} \\
\hline & & & 255 & 195 & 54 & - & \\
\hline \multirow{2}{*}{ Береза повислая (Betula pendula Roth.) } & \multirow{2}{*}{174} & \multirow{2}{*}{10,4} & 20 & 57 & 71 & 26 & \multirow{2}{*}{$\begin{array}{l}2,6 \\
1,9 \\
\end{array}$} \\
\hline & & & 50 & 89 & 35 & - & \\
\hline \multirow{2}{*}{ Клён платановидный (Acer platanoides L.) } & \multirow{2}{*}{292} & \multirow{2}{*}{17,4} & 78 & 128 & 66 & 20 & \multirow{2}{*}{$\begin{array}{l}2,1 \\
1,5 \\
\end{array}$} \\
\hline & & & 180 & 86 & 26 & - & \\
\hline \multirow{2}{*}{ Клен ясенелистный (Acer negundo $\boldsymbol{L}$.) } & \multirow{2}{*}{48} & \multirow{2}{*}{2,8} & 7 & 13 & 18 & 10 & \multirow{2}{*}{$\begin{array}{l}2,6 \\
2,4\end{array}$} \\
\hline & & & 5 & 17 & 26 & - & \\
\hline \multirow{2}{*}{ Ясень высокий (Fraxinus excelsior L.) } & & & 15 & 123 & 129 & 48 & 2,7 \\
\hline & 315 & 18,8 & 42 & 201 & 72 & - & 1,9 \\
\hline Ясень ланцетолистный (Fraxinus lanceolate & & & 5 & 10 & 5 & - & 2,0 \\
\hline & 20 & 1,2 & 11 & 8 & 1 & - & 1,5 \\
\hline & & & 2 & 15 & 26 & 10 & 2,8 \\
\hline Тополь бальзамический (Populus balsamifera L.) & 33 & 3,1 & 14 & 33 & 6 & - & 1,8 \\
\hline & & & 3 & 14 & 4 & 2 & 2,2 \\
\hline Тополь серебристый (Populus alba L.) & 23 & 1,4 & 11 & 10 & 2 & - & 1,6 \\
\hline Вез гпапкий (1لmus laevis Pall ) & 144 & & 9 & 55 & 50 & 30 & 2,9 \\
\hline Вяз Гладкии (UImus laevis Fau.) & 144 & 8,0 & 22 & 77 & 45 & - & 2,2 \\
\hline Рябина обикновенная (Sorbuc аиси naria $\boldsymbol{I}$ ) & 81 & 07 & 2 & 19 & 26 & 34 & 3,1 \\
\hline 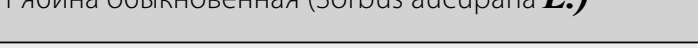 & 01 & O & 24 & 8 & 1 & - & 1,3 \\
\hline Яблоня пикая (Malus sylvestris Mill ) & 12 & 07 & 2 & 3 & 3 & 4 & 2,8 \\
\hline үолоня ДИкая (Ivalus sylvestns Мй.) & 12 & 0,1 & - & 8 & 4 & - & 2,3 \\
\hline Каштан конский обыкновенный (Aesculus & 1 & ( & - & 1 & - & - & 2,0 \\
\hline hippocastanum $\boldsymbol{L}$.) & 1 & 0,00 & - & 1 & - & - & 2,0 \\
\hline Боярышник обыкновенный (Crataegus laevigata & & ( & - & - & 1 & - & 3,0 \\
\hline (Poir.) DC.) & 1 & 0,06 & - & - & 1 & - & 3,0 \\
\hline & & & - & 1 & - & - & 2,0 \\
\hline Ива козья (Salıx caprea L.) & 1 & 0,06 & - & 1 & - & - & 2,0 \\
\hline & & & - & 1 & 2 & - & 2,7 \\
\hline Черемуха обыкновенная (Prunus padus $\boldsymbol{L}$.) & 3 & 0,18 & - & - & 3 & - & 3,0 \\
\hline & & & 231 & 708 & 515 & 218 & 2,5 \\
\hline всего деревьев: & $16 / 2$ & 100 & 614 & 734 & 276 & - & 1,8 \\
\hline Деревья хвойных пород & & & & & & & \\
\hline Fnь обыкновенная (Рісеа аріес (I ) Karst) & 29 & 537 & 2 & 6 & 9 & 12 & 3,1 \\
\hline Гль ооыкновенная (PICed dDIES (L.) Narst.) & 29 & 30,1 & 1 & 7 & 21 & - & 2,7 \\
\hline Лиственниша сибирская (I arix sibirica Ledeh) & 24 & 44.4 & 7 & 3 & 7 & 7 & 2,6 \\
\hline 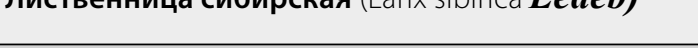 & 24 & 4,4 & 7 & 3 & 14 & - & 2,3 \\
\hline & 1 & & 1 & - & - & - & 1 \\
\hline Сосна ооыкновенная (PInus sylvestnis L.) & 1 & 1,8 & 1 & - & - & - & 1 \\
\hline & & & 10 & 9 & 16 & 19 & 2,2 \\
\hline всего деревьев: & 54 & 100 & 9 & 10 & 35 & - & 2,5 \\
\hline
\end{tabular}

где $\mathrm{K}_{c p}$. - средневзвешенная величина состояния породы;

Кэ - средневзвешенная величина эстетической оценки 
Таблица 2. Видовой состав, категории жизненного состояния и эстетическая оценка кустарниковой растительности, произрастающей на территории парка им. И.П. Кулибина г. Н. Новгорода

\begin{tabular}{|c|c|c|c|c|c|c|c|}
\hline \multirow[t]{2}{*}{ Наименование культуры } & \multirow{2}{*}{$\begin{array}{l}\text { Кол-во, } \\
\text { КВ.М. }\end{array}$} & \multirow[t]{2}{*}{ Доля,\% } & \multicolumn{4}{|c|}{$\begin{array}{l}\text { Категория } \\
\text { Эстетическая оценка }\end{array}$} & \multirow{2}{*}{$\begin{array}{l}\text { Kсp. } \\
\text { Kэ }\end{array}$} \\
\hline & & & 1 & 2 & 3 & 4 & \\
\hline \multirow{2}{*}{$\begin{array}{l}\text { Боярышник обыкновенный (Crataegus laevigata (Poir.) } \\
\text { DC.) }\end{array}$} & \multirow{2}{*}{67,7} & \multirow{2}{*}{16,7} & 3,5 & 28,2 & 29,5 & 6,5 & 2,6 \\
\hline & & & 3,5 & 39,2 & 25,0 & - & 2,3 \\
\hline \multirow{2}{*}{$\begin{array}{l}\text { Чубушник венечный (Philadelphus } \\
\text { coronarius) }\end{array}$} & \multirow{2}{*}{1,5} & \multirow{2}{*}{0,37} & - & & 1,5 & - & 3,0 \\
\hline & & & - & 1,5 & - & - & 2,0 \\
\hline \multirow{2}{*}{ Кизильник блестящий (Cotoneaster lucidus) } & \multirow{2}{*}{1,8} & \multirow{2}{*}{0,44} & - & - & 1,8 & - & 1,8 \\
\hline & & & - & 1,8 & - & - & 2,0 \\
\hline \multirow{2}{*}{$\begin{array}{l}\text { Спирея Вангутта (Spiraea vanhouttei (Briot) } \\
\text { Zabel) }\end{array}$} & \multirow{2}{*}{44,3} & \multirow{2}{*}{10,93} & & 10,7 & 20,6 & 13,0 & 3,0 \\
\hline & & & - & 17,7 & 26,2 & - & 2,6 \\
\hline \multirow{2}{*}{ Карагана древовидная (Caragana arborescens Lam.) } & \multirow{2}{*}{65,5} & \multirow{2}{*}{16,7} & - & 28,4 & 21,3 & 15,8 & 2,8 \\
\hline & & & - & 38,9 & 26,6 & - & 2,4 \\
\hline \multirow{2}{*}{ Барбарис обыкновенный (Berberis vulgaris $\boldsymbol{L}$.) } & \multirow{2}{*}{5,0} & \multirow{2}{*}{1,23} & - & - & 5 & - & 3 \\
\hline & & & - & - & 5 & - & 3 \\
\hline \multirow{2}{*}{ Сирень обыкновенная (Syringa vulgaris L.) } & \multirow{2}{*}{34,0} & \multirow{2}{*}{8,39} & - & 30 & 4 & - & 2,1 \\
\hline & & & - & 34 & - & - & 2,0 \\
\hline \multirow{2}{*}{ Клен ясенелистный (поросль) (Acer negundo $\boldsymbol{L}$.) } & \multirow{2}{*}{31,0} & \multirow{2}{*}{7,65} & - & 3,5 & 22,5 & 5,0 & 3,0 \\
\hline & & & - & - & 17,5 & 13,5 & 3,4 \\
\hline \multirow{2}{*}{$\begin{array}{l}\text { Клен платановидный (поросль) (Acer } \\
\text { platanoides L.) }\end{array}$} & \multirow{2}{*}{95,6} & \multirow{2}{*}{23,59} & - & 33,9 & 44,3 & 17,4 & 2,8 \\
\hline & & & - & 29,4 & 23,5 & 42,7 & 2,7 \\
\hline 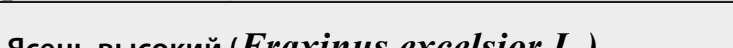 & & & - & 22,5 & 6,0 & - & 2,2 \\
\hline Ясень высокий (F raxinus excelsior L.) & 28,5 & 7,03 & 15,5 & 6,5 & 6,5 & - & 1,7 \\
\hline Tопопь серебnистьй (Ponulus alba $\boldsymbol{L}$ ) & 302 & 745 & - & 30,2 & - & - & 1,0 \\
\hline Іополь серебристыи (Populus alba L.) & 30,2 & 1,45 & 30,2 & - & - & - & 1,0 \\
\hline & & & 3,5 & 187,4 & 156,5 & 57,7 & 2,5 \\
\hline Всего кустарников: & 405,1 & 100 & 49,2 & 169,0 & 130,3 & 56,2 & 2,5 \\
\hline
\end{tabular}

Фитопатологическое состояние древесных пород оценивалось визуально по общепринятым методикам. Эстетическая оценка зеленых насаждений проводилась по методике В.А. Агальцевой, 1993 г. по трехбалльной системе: 1 балл - высокая, 2 балла - средняя, 3 балла - низкая [8], при этом деревья подлежащие вырубке не учитывались. Выявление вредителей и болезней осуществлено по методике И.И. Журавлева, 1979 г. [9].

\section{Результаты и обсужление}

Зеленые насаждения на территории Нижнего Новгорода выполняют важнейшие средообразующие и эстетические функции. Широко известна роль зеленых насаждений как звукопоглощающего барьера, аккумулятора взвешенных веществ и вредных примесей, содержащихся в атмосферном воздухе города. Деревья и кустарники в вегетационный период активно обогащают атмосферу города кислородом, увеличивают влажность воздуха. Сомкнутые насаждения формируют особую фитосреду, которая характеризуется уве- личением влажности воздушных масс, уменьшением скорости ветра, более плавной амплитудой суточного изменения температур, по сравнению с аналогичными показателями открытых пространств. Некоторые биологические виды древесно-кустарниковых пород, особенно хвойные, выделяют фитонциды, которые имеют существенное оздоровительное значение. Не менее важен эстетический эффект от декоративных свойств зеленых насаждений, которые смягчают негативные факторы урбанизации. Однако свои положительные свойства зеленые насаждения проявляют только при условии их нормального развития, в виду чего ослабленные, имеющие низкие эстетические характеристики и мало привлекательные древесно-кустарниковые породы должны заменяться более устойчивыми к городским условиям, обладающими при этом привлекательными декоративными качествами.

Газонное покрытие создает фон для дендрологических и цветочных композиций, имеет большое санитарно-гигиеническое и эстетическое значение, и формирует целостность архитектурно-ландшафтного комплекса. 
В настоящее время травянистый покров парка сильно деградирован, травостой редкий, засорен или отсутствует из-за затенения, значительная часть газона вытоптана. Площадь проективного покрытия составляет $30 \%$.

В результате инвентаризации зеленых насаждений установлено, что на территории парка произрастает 1672 экз. древесных насаждений лиственной породы. Видовой состав зеленых насаждений парка им. И.П. Кулибина г. Нижнего Новгорода представлен 24 видами, относящимися к 21 роду, 11 семействам и 2 отделам Количественная характеристика видового состава зеленых насаждений парка им. И.П. Кулибина, оценка их жизненного и эстетического состояния приведены в таблице 1.

Зеленые насаждения представлены древесной растительностью лиственных и хвойных пород деревьев, а также кустарниковой растительностью (таблица 2). Доминирующей древесной культурой среди лиственных пород в парке им. И.П. Кулибина является липа сердцевидная (Tilia cordata Mill.), Она составляет более $30 \%$ от общего числа деревьев лиственных пород. Субдоминантными листвеными породами являются ясень высокий (Fraxinus excelsior L.) и клён платановидный (Acer platanoides L.) 18,8\% и 17,4\% соотвественно. Единичными экземплярами представлены древесные культуры: каштан конский обыкновенный (Aesculus hippocastanum L., боярышник обыкновенный (Crataegus laevigata (Poir.) DC.), ива козья (Salix caprea L.). Среди хвойных пород преобладает ель обыкновенная (Picea abies (L.) Karst.), доля которой составляет более половины всех деревьев хвойных пород (53,7\%.). Доминирующим видом кустарниковой растительности является поросль клена платановидного (Acer platanoides L.) 23,6\%.

Среднее значение жизнеустойчивости у большинства лиственных пород деревьев соответствует ослабленному состоянию (42,3\%), основное число даной категории древесных культур составляют насаждения липы сердцевидной (Tilia cordata Mill.) - 268 экз., клёна платановидного (Acer platanoides L.) - 128 экз., ясеня высокого (Fraxinus excelsior L.) - 123 экз. Чуть менее трети всех деревьев лиственных пород $(30,8 \%)$ и хвойных $(29,6 \%)$, а также $38,6 \%$ кустарниковых насаждений имеют сильно-ослабленное состояние и нуждаются в проведении кронирования, обрезки сухих веток, лечение стволов.

Эстетическое состояние насаждений зависит от целого ряда факторов: вида и возраста древесных и кустариковых насаждений, уровня антропогенной и рекреационной нагрузки, структурной организации и плотности размещения насаждений. Наиболее вы- сокий класс эстетики $(1,5)$ среди лиственных древесных культур отмечен для клена плантавидного (Acer platanoides L.), ясеня ланцетолистного (Fraxinus lanceolate L.). Эстетика кустарников оценена несколько ниже, чем у деревьев, так средняя оценка 2,0 отмечена у чубушника венечного (Philadelphus coronarius), кизильника блестящего (Cotoneaster lucidus) и сирени обыкновенной (Syringa vulgaris L.).

Санитарная оценка зеленых насаждений выявила их неудовлетворительное состояние. Ослабление деревьев сопровождается усыханием, на долю усыхающих ветвей приходится свыше 50\% всех повреждений. Многие деревья имеют механические повреждения, сухобочины и нуждаются в лечении, при этом велика доля гнилевых патологических факторов. У лип и кленов, примыкающим к улицам Белинского и Горького отмечено снижение прироста, измельчение листвы, краевой ожог. Среди болезней лиственных пород преобладают некрозно-раковые, что обусловлено возрастом насаждений, высотой деревьев. Так, средняя высота прикрепления первого живого сучка по породам составила: у липы сердцевидной (Tilia cordata Mill.) - 8,48 м, вяза гладкого (Ulmus laevis Pall.) - 6,34 м, клена платановидного (Acer platanoides L.) - 4,97 м, ясеня высокого (Fraxinus excelsior L.) - 3,8 м, березы повислой (Betula pendula Roth.) - 8,08 м, рябины обыкновенной (Sorbus aucuparia L.) - 2,57 м, тополя бальзамического (Populus balsamifera L.) - 11,3 м, тополя серебристого (Populus alba L.) - 11,5 м. Некрозные болезни обнаружены в основном на породах с тонкой корой - рябине обыкновенной (Sorbus aucuparia L.) и ясене высоком (Fraxinus excelsior L.). Преимущественно распространены туберкуляриевый, нуммуляриевый и цитофомовый некроз. Гиперпластические бактериозы в виде опухолевидного рака отмечены на клене ясенелистном (Acer negundo L.). Бактериозы в виде слизетечения отмечены на березе повислой (Betula pendula Roth.), клене ясенелистном (Acer negundo L.), рябине обыкновенной (Sorbus aucuparia L.) и липе сердцевидной (Tilia cordata Mill.).

Биологическое разрушение древесины стволов вызвано трутовиками: ложным - Phellinus igniarius L. (отмечен на клене, липе, вязе, тополе), серно-желтым - Laetiporus sulphureus (тополь, ясень), настоящим - Fomes fomentarius L. (береза, липа), кленовым трутовиком - Oxyporus populinus Fr. (клен), щелевиком обыкновенным - Schizophyllum commune Fr. (ясень, клен, липа). Гниль стволов визуально отмечена как в виде плодовых тел трутовиков, так и в виде дупла (начальная стадия или конечная стадии).

Из болезней на листьях клена (подрост) отмечено их поражение мучнистой росой (степень средняя, пораже- 
но от 10 до 35\% листьев) черной пятнистостью (слабая степень, до 596 листьев). Мучнистая роса отмечена также и на карагане древовидной (Caragana arborescens Lam.). На листьях липы встречалась кремовая пятнистость (10-15\%). Сильной поврежденности листьев вредителями не отмечено, лишь на отдельных липах в нижней части встречались листья поврежденные слизистым липовым пилильщиком (Caliroa annulipes L.) На клене единично встречался многоядный трубковерт (Byctiscus betulae L.). Бурым войлочным липовым клещиком (Eriophyes leiosoma Nal.) на отдельных деревьях было повреждено до 75\% листьев, на березе и клёне - березовый войлочный (Eriophyes Rudis Typicus Nal.) и единично - кленовый войлочный клещики (Aceria pseudaplatani (Corti).), на ели - еловый хермес (Adelges tardus) - 3,5\%.

\section{Зак^ючение}

Парк имени И.П. Кулибина в г. Н. Новгороде входит в реестр озелененных территорий общего пользования. Площадь, занятая зелеными насаждениями, составляет более $2 / 3$ от общей площади парка. Основную долю в структуре зеленых насаждений составляют древесные лиственные культуры, их количество составляет 1672 экз., кустарники занимают площадь 405,1 кв. м.
Преобладающей лиственной культурой является липа сердцевидная (Tilia cordata Mill.), среди кустаринков доминирует поросль клена платановидного (Acer platanoides L.) $-23,6 \%$.

Значительная доля зеленых насаждений парка характеризуется ослабленным и сильно-ослабленным состоянием. Санитарно-патологическая оценка свидетельствует о неудовлетворительном состоянии большинства произрастающих на территории парка древесных культур. На каждой исследуемой древесной культуре выявлено два и более патологических признака. Среди основных болезней зеленых насаждений парка им. И.П. Кулибина преобладают бактериозы и некрозно-раковые опухоли различной этиологии, поражение древесины трутовиками. Неудовлетворительное состояние зеленых насаждений сквера обусловлено возрастом и ослабленным иммунитетом древостоя, произрастающего в городских условиях, а также связано с недостаточностью и низким качеством осуществления уходовых мероприятий за озелененными территориями общего пользования. Парк им. И.П. Кулибина остро нуждается в благоустройстве, включая первоочередную задачу по периодической инвентаризации, реконструкции и уходу за существующими зелеными насаждениями.

\section{ЛИТЕРАТУРА}

1. Аткина Л.И., Гневнов Е.С. Оценка эстетического состояния насаждений парков окраин г. Екатеринбурга и пути их улучшения // Хвойные бореальной 3оны, XXXI, № 1-2. 2013. С. 36-41.

2. Козлов А.В., Медведева Е.Б. Оценка обеспеченности горожан озелененными территориями в условиях современного развития города Нижнего Новгорода // Приволжский научный вестник. 2015. № 12(1)-52. С. 15-18.

3. Кириллов С.Н., Половинкина Ю.С. Оценка состояния зеленых насаждений общего пользования г. Волгограда // Вестн. Волгогр. гос. ун-та. Сер. 11, Естеств. науки. 2013. № 1 (5). С. 29-34.

4. Рунова Е.М., Гаврилин И.И., Гаврилина М.К. Комплексная оценка экологического состояния древесных растений урбоэкосистемы Братска по интегральному показателю устойчивости // Хвойные бореальной зоны, XXX, № 3-4. 2012. С. 312-315.

5. Иевская А.А., Корсунова Т.М. Изучение состояния растительности в системе озеленения города Улан-Удэ // Самарский научный вестник. 2020. Т. 9, № 2 (31). C. 54-59.

6. Копосова Н.Н., Шайбекова М.Р. Проектирирование парка «Мещерское озеро» как структурного элемента экологического каркаса города Нижнего Новгорода // Успехи современного естествознания. 2017. № 7. С. 81-85.

7. Воронина 0.Н. Ландшафтная архитектура нижегородскх парков. Н.Н.: Полиграфцентр ННГАСУ. 2013. 263 с.

8. Агальцова В.А. Основы лесопаркового хозяйства. М.: МГУЛ. 2008. 213 с.

9. Ж Журавлев И.И., Крангауз Р.А. Яковлев В.Г. Болезни лесных и древесных кустарников. М.: Лесная промышленность. 1974.160 с.

( ) Вершинина Ирина Валерьевна ( vershinina.iv@gmail.com ), Рябова Евгения Павловна ( riabova_97@mail.ru ).

Журнал «Современная наука: актуальные проблемы теории и практики» 